This PDF is a selection from a published volume from the National Bureau of Economic Research

Volume Title: Explorations in the Economics of Aging

Volume Author/Editor: David A. Wise, editor

Volume Publisher: University of Chicago Press

Volume ISBN: 0-226-90337-0

ISBN13: 978-0-226-90337-8

Volume URL: http://www.nber.org/books/wise09-2

Conference Date: May 2009

Publication Date: March 2011

Chapter Title: Differential Mortality by Income and Social Security Progressivity

Chapter Authors: Gopi Shah Goda, John B. Shoven, Sita Nataraj Slavov

Chapter URL: http://www.nber.org/chapters/c11940

Chapter pages in book: (189 - 204) 


\title{
Differential Mortality by Income and Social Security Progressivity
}

\author{
Gopi Shah Goda, John B. Shoven, \\ and Sita Nataraj Slavov
}

\subsection{Introduction}

There is a widespread belief that people with low lifetime labor income have higher age-specific mortality and lower remaining life expectancies at age sixty or sixty-five than those with middle or high lifetime earnings. Historically, there was very little evidence to either support or undermine this belief. The evidence that did exist found mortality differences by current labor income that could not be easily translated to measures based on lifetime income due to reverse causality issues: someone with poor health status is likely to have low current earnings as well as high mortality. Recently, however, new estimates of the mortality gap by lifetime income and its trend over time have been produced.

In this chapter, we assess the implications of differential mortality by lifetime income for the progressivity of the "old-age" or retirement portion of Social Security. Social Security has a highly progressive benefit formula to determine monthly payments in that those with low lifetime earnings get a much higher replacement rate than those with high lifetime earnings. For example, Social Security might replace 70 percent of earnings for someone with a full-length career in the bottom quartile of the earnings distribution,

Gopi Shah Goda is the Postdoctoral Fellow Program coordinator and research scholar at the Stanford Institute for Economic Policy Research. John B. Shoven is the Charles R. Schwab Professor of Economics at Stanford University, and a research associate of the National Bureau of Economic Research. Sita Nataraj Slavov is associate professor of economics at Occidental College.

This research was supported by the National Institute of Aging through grant \#P30AG012810 to the National Bureau of Economic Research. The opinions and conclusions expressed are solely those of the authors and do not represent the opinions or policy of NIA or any agency of the federal government. The authors would like to thank Andrew Hung and Mod Lueprasitsakul for superb research assistance. 
but only 30 percent of earnings for someone in the top quartile. The rationale for this pattern is that those in the higher earnings brackets presumably have more opportunities to accumulate pensions and private saving to help finance their retirement.

However, the recent studies on the mortality gap by lifetime income suggest that at least some of this progressivity is counterbalanced by the longer average lifetimes experienced by higher lifetime income recipients of Social Security. Because the old-age benefits of Social Security benefits are paid as a life annuity, groups with higher life expectancies have higher returns than those with lower life expectancies. We do not examine the disability portion of Social Security in this study. Disability benefits are presumably progressive in that those with lower lifetime earnings are more likely to have experienced partial or total disabilities.

The recent literature on differential mortality by lifetime income allow us to reassess the progressivity of the retirement portion of Social Security by calculating internal rates of return and net present values for the program under assumptions of differential mortality. We compare these measures of progressivity to the same measures calculated, assuming all individuals experience average population mortality rates. Under the assumption of constant mortality across lifetime income subgroups, the Social Security system is progressive regardless of the measure shown. However, a good deal of the progressivity is undone or even reversed when differential mortality is taken into account. The results are similar for both stylized earners at different points of the earnings distribution and actual workers' earnings histories.

The chapter proceeds as follows. Section 6.2 discusses the literature on Social Security progressivity and differential mortality by income. Section 6.3 describes the earnings and mortality data used, as well as the way that earnings histories and differential mortality estimates were developed from these data sources. The methodology used to calculate internal rates of return and net present values is described in section 6.4, and results are presented in section 6.5. Section 6.6 concludes.

\subsection{Literature Review}

A handful of studies have analyzed the relationship between mortality and Social Security progressivity. Early studies include Aaron (1977), Steuerle and Bakija (1994), and Garrett (1995). These studies calculate returns to Social Security for hypothetical workers and suggest that differential mortality reduces the amount of progressivity in Social Security. More recent studies, including Coronado, Fullerton, and Glass (2000) and Liebman (2001), examine the redistribution in the old-age portion of Social Security more generally. Coronado, Fullerton, and Glass (2000) proceed in several steps, reclassifying Social Security recipients by different measures of income and incorporating mortality probabilities that differ by income. They conclude 
that the system is far less progressive than it first appears, and may even be regressive under certain assumptions. Liebman (2001) uses a microsimulation model to show that Social Security becomes less redistributive when mortality is assumed to differ by race and education. Both of these more recent studies perform calculations for a data set of individual earning histories based on a combination of survey, administrative, and imputed data. The Congressional Budget Office (CBO 2006) makes the point that when disability and survivor benefits are taken into account, Social Security is more progressive than when only retirement benefits are considered.

Many of these studies use estimates of differential mortality from several decades ago. Garrett (1995) uses stylized earnings histories and mortality differentials estimated in the 1960s and 1970s in Kitagawa and Hauser (1973). Coronado, Fullerton, and Glass (2000) apply a crude adjustment to mortality ratios based on mortality differentials by annual income. The authors acknowledge that annual income may be lower due to illness preceding death, and that their estimates may be biased as a result of reverse causality. However, the estimates they use from Rogot, Sorlie, and Johnson (1992) were the best available estimates of differential mortality by income available at the time.

Recent research has produced new estimates of how mortality differs by lifetime income, as well as suggestive evidence that the mortality inequality by income has been growing over time (Singh and Siahpush 2006; Cristia 2007; Waldron 2007; CBO 2008; Jemal et al. 2008; Duggan, Gillingham, and Greenlees 2006). These studies are broadly consistent in their conclusions, and are based on richer and more recent data than previous estimates of differential mortality. In this study, we rely on estimates in Cristia (2007) and Waldron (2007), as described in the following section, to generate mortality probabilities that differ by measures of lifetime income.

\subsection{Data}

\subsubsection{Mortality}

We begin with mortality data obtained by request from the Social Security Administration. The data consists of cohort life tables that underlie the 2007 Trustees Report. For cohorts born in 1925 and later, Social Security provides projected mortality rates under three different alternatives (I, II, III). The intermediate scenario, or Alternative II, is used in our analysis for cohorts born after 1925 .

Waldron (2007) provides estimates of odds ratios (the mortality rate of the bottom half of the income distribution relative to the mortality rate of the top half of the income distribution) for men in five cohorts, broken down into five-year age groups between sixty and eighty-nine. The measure of income used in Waldron (2007) is average nonzero earnings from age 
Table 6.1

Mortality of bottom half relative to top half of lifetime income distribution (males)

\begin{tabular}{lcccccc}
\hline & \multicolumn{7}{c}{ Age } \\
\cline { 2 - 7 } Year of birth & $60-64$ & $65-69$ & $70-74$ & $75-79$ & $80-84$ & $85-89$ \\
\hline $1912-1915$ & $\mathbf{1 . 2 7}$ & $\mathbf{1 . 2 4}$ & $\mathbf{1 . 2 0}$ & $\mathbf{1 . 1 3}$ & $\mathbf{1 . 0 9}$ & $\mathbf{0 . 9 4}$ \\
$1916-1919$ & $\mathbf{1 . 5 1}$ & $\mathbf{1 . 3 6}$ & $\mathbf{1 . 3 4}$ & $\mathbf{1 . 2 0}$ & $\mathbf{1 . 0 5}$ & 0.90 \\
$1920-1923$ & $\mathbf{1 . 5 0}$ & $\mathbf{1 . 4 0}$ & $\mathbf{1 . 3 4}$ & $\mathbf{1 . 3 1}$ & 1.22 & 1.07 \\
$1924-1927$ & $\mathbf{1 . 5 1}$ & $\mathbf{1 . 5 3}$ & $\mathbf{1 . 4 8}$ & 1.40 & 1.31 & 1.16 \\
$1928-1931$ & $\mathbf{1 . 7 1}$ & $\mathbf{1 . 6 1}$ & 1.57 & 1.49 & 1.39 & 1.24 \\
$1932-1935$ & $\mathbf{1 . 7 5}$ & $\mathbf{1 . 7 3}$ & 1.69 & 1.61 & 1.51 & 1.36 \\
$1936-1938$ & $\mathbf{1 . 8 4}$ & 1.78 & 1.73 & 1.65 & 1.56 & 1.41 \\
\hline
\end{tabular}

forty-five to fifty-five. Waldron's estimates are shown in bold in table 6.1. The first cell, for example, indicates that an individual between the ages of sixty and sixty-four in the bottom half of the lifetime income distribution has a probability of dying that is 1.27 times higher than an individual in the top half of the distribution. Note that for all cohorts, these odds ratios decline as individuals age. In fact, mortality inequality disappears by the time the 1912 to 1915 birth cohort reaches ages eighty-five to eighty-nine (the bottom half is even estimated as having a slightly lower mortality rate).

Waldron's estimates end at the last observed age for each cohort-for example, while estimates are available through age eighty-nine for the 1912 to 1915 cohort, they are only available through age sixty-four for the 1936 to 1938 cohort. We perform a back-of-the-envelope calculation to estimate odds ratios for the remaining unobserved cohort/age group combinations. First, for each cohort, we compute the difference in the observed odds ratio when moving from one age group to the next. For example, for the 1912 to 1915 cohort, the odds ratio decreases by 0.03 when moving from the sixty to sixtyfour age group to the sixty-five to sixty-nine age group; it falls by 0.04 when moving from sixty-five to sixty-nine to seventy to seventy-four. For each age group, we then compute the average difference across cohorts. For example, when moving from the sixty to sixty-four age group to the sixty-five to sixtynine age group, the average decline (across the six cohorts for which we have observed odds ratios) in the odds ratio is 0.06 . We use the average decreases in the odds ratios to estimate odds ratios for the missing cohort/age groups. In the case of the 1936 to 1938 cohort, the odds ratio is assumed to fall by 0.06 (from 1.84 to 1.78). Thus, we assume that mortality inequality declines with age in a similar way for each cohort. Our estimates are shown in italic.

We develop a similar table for women by incorporating estimates from Cristia (2007), which suggest that there is less mortality inequality among women. Cristia's estimates suggest that a male aged sixty-five to seventy-five in the second quintile (which includes the twenty-fifth percentile) has a mortality rate that is 1.14 times the average (for males in that age group), while a 
Mortality of bottom half relative to top half of lifetime income distribution (females)

\begin{tabular}{lcccccc}
\hline & \multicolumn{7}{c}{ Age } \\
\cline { 2 - 7 } Year of birth & $60-64$ & $65-69$ & $70-74$ & $75-79$ & $80-84$ & $85-89$ \\
\hline $1912-1915$ & 1.13 & 1.10 & 1.07 & 1.00 & 0.97 & 0.84 \\
$1916-1919$ & 1.34 & 1.21 & 1.19 & 1.07 & 0.93 & 0.80 \\
$1920-1923$ & 1.33 & 1.24 & 1.19 & 1.16 & 1.08 & 0.95 \\
$1924-1927$ & 1.34 & 1.36 & 1.32 & 1.24 & 1.16 & 1.03 \\
$1928-1931$ & 1.52 & 1.43 & 1.39 & 1.32 & 1.24 & 1.10 \\
$1932-1935$ & 1.56 & 1.54 & 1.50 & 1.43 & 1.34 & 1.21 \\
$1936-1938$ & 1.64 & 1.58 & 1.54 & 1.47 & 1.39 & 1.25 \\
\hline
\end{tabular}

male aged sixty-five to seventy-five in the fourth quintile (which includes the seventy-fifth percentile) has a mortality rate that is 0.94 times the average. Thus, the odds ratio for the second quintile relative to the fourth is 1.21. Similarly, a woman aged sixty-five to seventy-five in the second quintile has a mortality rate that is 1.11 times the average, while a woman aged sixty-five to seventy-five in the fourth quintile has a mortality rate that is 1.03 times the average. The implied odds ratio for the second to fourth quintiles is 1.08. The second/fourth quintile odds ratio for women is 88.9 percent of the second/fourth quintile odds ratio for men. We assume the top half/bottom half odds ratios for women are 88.9 percent of the corresponding male odds ratios - these are shown in table 6.2.

In our simulations, we consider the mortality experience of four cohorts: $1915,1923,1931$, and 1939. For these cohorts, we model inequality by using the odds ratios associated with the 1912 to 1915,1920 to 1923,1928 to 1931 , and 1936 to 1938 birth cohorts, respectively. We construct age-specific mortality rates for the bottom half and top half in such a way that their ratio is equal to the relevant odds ratio from tables 6.1 and 6.2, and their average is equal to the overall mortality rate from the Social Security Administration's cohort life table. For individuals above age eighty-nine, we apply the odds ratios for ages eighty-five to eighty-nine. For individuals aged twenty to fifty-nine, we apply the odds ratios for the sixty to sixty-four age group. Cristia's (2007) results suggest that mortality inequality is even higher among age groups below the age of sixty. Thus, applying the sixty to sixty-four odds ratios to younger age groups biases the results in the direction of less mortality inequality.

We calculate several measures of life expectancy and mortality risk from the resulting mortality tables. The results are summarized in table 6.3. They show that the bottom half has shorter life expectancies and lower survival rates than median income workers, and the top half has longer life expectancies and higher rates of survival. In addition, the tables show that the projected differences in mortality are widening: while the differential of the 
Table 6.3

Projected mortality measures by gender, cohort, and lifetime income

\begin{tabular}{|c|c|c|c|c|c|c|}
\hline \multirow[b]{2}{*}{ Cohort } & \multicolumn{3}{|c|}{ Males } & \multicolumn{3}{|c|}{ Females } \\
\hline & Top half & Med income & Bottom half & Top half & Med income & Bottom half \\
\hline \multicolumn{7}{|c|}{ Cohort life expectancy at age 20} \\
\hline 1915 & 52.25 & 50.91 & 49.65 & 57.93 & 57.63 & 57.35 \\
\hline 1923 & 54.86 & 52.55 & 50.48 & 59.94 & 58.87 & 57.84 \\
\hline 1931 & 57.34 & 54.18 & 51.49 & 61.61 & 59.79 & 58.11 \\
\hline 1939 & 59.35 & 55.65 & 52.63 & 63.06 & 60.72 & 58.67 \\
\hline \multicolumn{7}{|c|}{ Cohort life expectancy at age 60} \\
\hline 1915 & 18.95 & 18.26 & 17.60 & 22.99 & 23.00 & 23.03 \\
\hline 1923 & 20.56 & 19.28 & 18.13 & 23.78 & 23.25 & 22.73 \\
\hline 1931 & 22.16 & 20.22 & 18.59 & 24.74 & 23.56 & 22.49 \\
\hline 1939 & 23.58 & 21.89 & 19.91 & 25.72 & 24.03 & 22.58 \\
\hline \multicolumn{7}{|c|}{ Cohort life expectancy at age 65} \\
\hline 1915 & 15.72 & 15.20 & 14.70 & 19.13 & 19.21 & 19.32 \\
\hline 1923 & 17.07 & 16.05 & 15.13 & 19.80 & 19.41 & 19.04 \\
\hline 1931 & 18.47 & 16.83 & 15.45 & 20.65 & 19.66 & 18.75 \\
\hline 1939 & 19.69 & 18.25 & 16.52 & 21.56 & 20.05 & 18.77 \\
\hline \multicolumn{7}{|c|}{ Probability of survival to age 65 conditional on survival to age 20} \\
\hline 1915 & 0.708 & 0.676 & 0.645 & 0.817 & 0.807 & 0.796 \\
\hline 1923 & 0.762 & 0.712 & 0.665 & 0.853 & 0.831 & 0.809 \\
\hline 1931 & 0.805 & 0.745 & 0.689 & 0.878 & 0.848 & 0.820 \\
\hline 1939 & 0.838 & 0.791 & 0.738 & 0.896 & 0.865 & 0.835 \\
\hline
\end{tabular}

cohort life expectancy at age twenty between high income and low income men born in 1915 was 0.58 years, it is projected to grow to 4.4 years for the 1939 cohort. Differentials are smaller for women (by construction) and have the same increasing pattern.

We believe that the income-specific mortality information of Waldron and Cristia is superior to previous estimates. Still, the data are limited. Rather than analyzing the mortality differences between those in the top and bottom halves of the lifetime earnings distributions, we would have liked to have the information by lifetime income decile so that we could examine the mortality experience of the genuinely poor versus those at other parts of the distribution. It seems likely that the extent of mortality inequality is even greater than reflected in the top half/bottom half analysis.

\subsubsection{Earnings}

We analyze measures of progressivity calculated for stylized workers with earnings at the twenty-fifth, fiftieth, and seventy-fifth percentiles as well as for a large sample of actual earnings histories. The earnings data we use are based on the Benefits and Earnings Public-Use File, 2004. This data source contains earnings histories and other administrative data for a 1 percent random sample of Social Security beneficiaries in December 2004. Because 
Social Security did not record annual earnings until 1951 but did record aggregated earnings over the period 1937 to 1950, we omit individuals who had nonzero earnings prior to 1951 so that our final sample contains complete earnings histories. We also limit the sample to those individuals who are receiving Social Security retirement benefits based on their own earnings history, as the data do not contain any way to link married couples. The remaining sample contains 125,829 observations.

We develop earnings to match the cohorts for whom we have estimates of differential mortality. The youngest cohort we examine is the cohort born in 1936 to 1939. We pool the cohorts in the Benefits and Earnings PublicUse file born in these years (33,632 men and 20,429 women), and calculate each individual's average nonzero earnings from age forty-five to fifty-five, denoted by $\overline{E A R N_{45-55}}$. This figure is used to classify earners into the bottom half and the top half of the earnings distribution, consistent with Waldron (2007). The classification is done separately by year of birth and by gender. In our subsequent analysis under the assumption of differential mortality, the individuals classified into the "top half" category are assumed to experience mortality rates developed for the top half of the earnings distribution, and individuals classified into the "bottom half" category are assumed to experience the less favorable mortality rates developed for the bottom half of the earnings distribution. The mortality rates are based on Waldron (2007), as described previously.

After individuals are classified into these two earnings groups, we generate six stylized earnings histories: for the twenty-fifth, fiftieth, and seventy-fifth percentile male worker as determined by $E A R N_{45-55}$, and a similar set for women. To construct earnings histories for earlier cohorts, we scale back earnings appropriately using Social Security's average wage index. ${ }^{1}$

The earnings profiles for the stylized workers for the 1936 to 1939 birth cohorts are shown in figure 6.1. The earnings are reported in nominal dollars in the year they were earned. The stylized workers at the seventy-fifth percentile experience the steepest increases by age. The last year of earnings observed in the data is 2003, and we assume that 2003 marks the final year of work for this sample.

While examining the progressivity of the stylized workers illustrates the impact differential mortality can have on the distribution of retirement benefits and allows comparison to earlier literature, the stylized earnings histories are unrealistic because the position of actual workers in the earnings distribution moves from one year to the next and people do not stay at the twenty-fifth or seventy-fifth percentile of the income distribution for their entire career. Therefore, we also supplement our analysis with measures of progressivity computed for each worker in our original sample.

1. This method is used instead of generating each cohort's earnings histories directly from the sample because of the lack of annual earnings data from 1937 to 1950. 


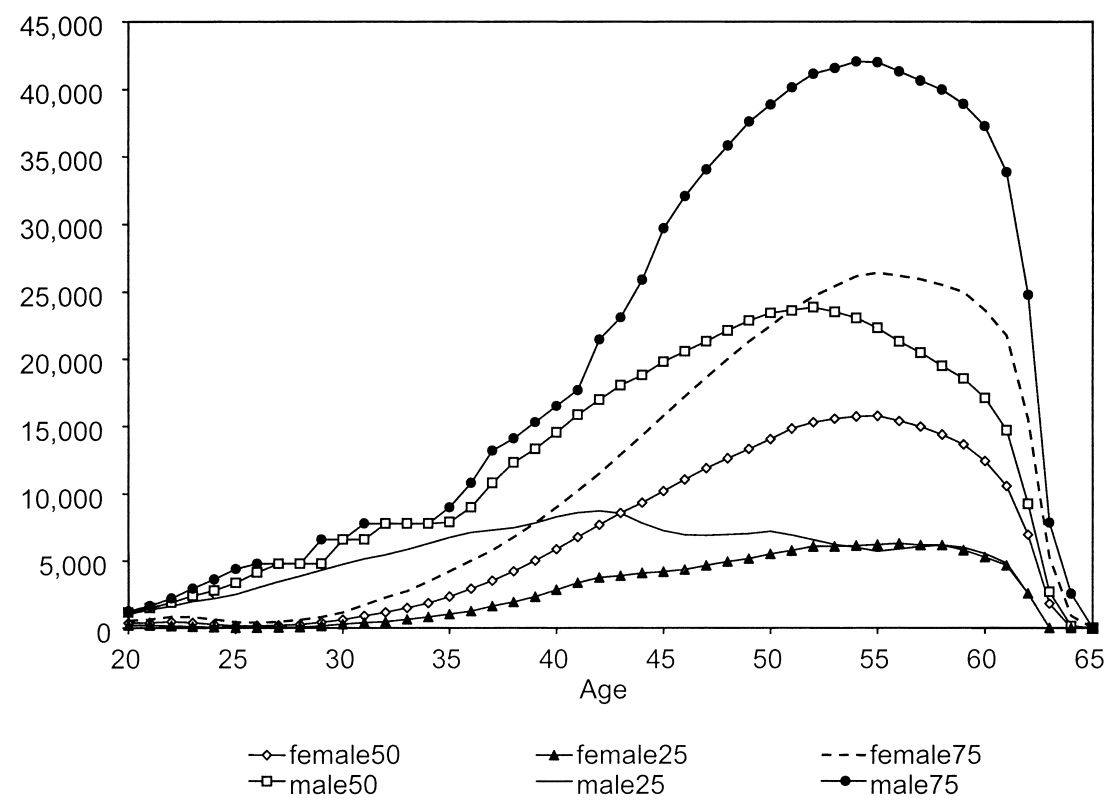

Fig. 6.1 Stylized earnings profiles, birth cohorts 1936-1939

\subsection{Measures of Progressivity}

We derive measures of the progressivity of Social Security for both the stylized earnings profiles described in the previous section, as well as the sample of earnings histories used to generate the stylized profiles. First, we calculate each worker's Social Security benefits under current law using the worker's whole series of earnings. Each year of earnings is first indexed forward to age sixty of the worker using Social Security's average wage index series. From these indexed earnings, the highest thirty-five values are then added up and divided by 420 to arrive at the Average Indexed Monthly Earnings, or AIME. The AIME includes zeroes if an individual worked less than thirty-five years.

Next we determine each individual's Primary Insurance Amount (PIA) by using the current (2008) nonlinear PIA formula, which encompasses the progressivity in the Social Security system. For retirees turning sixty-two in 2008, the PIA is equal to 90 percent of the first $\$ 711$ of AIME, plus 32 percent of AIME above $\$ 711$ and less than $\$ 4,288$, plus 15 percent of AIME above $\$ 4,288$. For retirees in earlier cohorts, the thresholds (commonly referred to as bend points) are adjusted with the average wage index. Through this formula, workers with lower levels of AIME receive higher replacement rates from Social Security. The full PIA is payable to workers who retire at the designated normal retirement age for their cohort. The PIA is paid as an inflation-indexed life annuity, which ends at death. We assume 
the worker claims benefits at his or her normal retirement age, and the stream of benefits represents the cash outflows from the program.

The Social Security payroll tax is 12.4 percent, paid equally by the employee and the employer; however, it is commonly assumed that the employee bears the full amount of this tax. The portion used to fund retirement and survivor benefits is 10.6 percent, and the remaining 1.8 percent is used to fund disability benefits. We therefore use 10.6 percent of earnings in each year to represent the cash inflows to the program corresponding to the Social Security retirement benefits calculated for each worker.

We convert these nominal cash flows to real cash flows using the Consumer Price Index (CPI), and finally adjust the stream of cash flows for mortality using the tables described in the previous section. Each set of cash flows is subject to two different sets of mortality assumptions. Under homogenous mortality, all cash flows are adjusted using population-average mortality appropriate for the worker's birth cohort. Under differential mortality, all cash flows are adjusted using the income-specific mortality table applicable to the worker. For the stylized workers, the twenty-fifth percentile worker is the median of the bottom half and is therefore assumed to experience the mortality rates constructed for the bottom half. Similarly, the seventy-fifth percentile worker is assigned top half mortality, and the median worker uses the average mortality rates of the population. For the actual worker's earnings histories, we classify workers by calculating $\overline{E A R N_{45-55}}$ and apply top half mortality to those with $\overline{E A R N_{45-55}}$ above the median and bottom half mortality to those with $\overline{E A R N_{45-55}}$ below the median.

Under both sets of mortality assumptions, we present two measures of Social Security progressivity: the internal rate of return (IRR), and the net present value (NPV). The IRR is the rate of return that equates the present value of cash inflows to the present value of cash outflows. We compute the IRRs of the expected cash flows from Social Security (as just described). Thus, our IRR measure can be interpreted as the return earned in the aggregate by individuals with the same earnings history within a particular cohort. $^{2}$ A rate of return of 2 percent indicates that Social Security is comparable to a safe investment that earns 2 percent each year. The NPV is simply the difference between the discounted present value of all expected cash inflows and outflows, calculated using a safe real rate of return of 2 percent. The NPV is reported in constant 2008 dollars.

2. Because the IRR is nonlinear, this is different from the expected IRR earned by an individual with that earnings profile. To find the expected IRR for an individual, we would have to compute the IRRs conditional on survival to every possible age, and then calculate the expected value using the relevant mortality profile. The difficulty in performing this calculation is that if the individual dies before reaching retirement age, the IRR is negative infinity. This distinction is not important for our other measure, the net present value (NPV). Because the NPV is linear, the NPV for a group in the aggregate is the same as the expected NPV for a member of the group. 
It is important to emphasize that we are not calculating the rates of return to Social Security actually experienced by people born in 1915, 1923, 1931, and 1938. Rather, what we are analyzing is how they would have done if the 2008 structure of Social Security (adjusted backwards for changes in average wages) had been in effect for their entire lifetimes. By assuming workers in all cohorts receive benefits based on current law, we are ignoring the large start-up gains that older cohorts received because of the growth of Social Security in the 1950s and 1960s and its pay-as-you-go nature. This assumption allows us to isolate the changes in progressivity due solely to changes in mortality and mortality inequality. In reality, older cohorts earned far higher internal rates of return as they paid Social Security taxes during times of relatively low tax rates, but received benefits based on more generous benefit formulas.

\subsection{Results}

We begin by computing internal rates of return and net present values (as described earlier) for our stylized workers. These results are shown in table 6.4. In each case the "unadjusted" column contains the results obtained using homogeneous mortality. The "adjusted" columns use differential mortality. That is, we use the mortality profile of the bottom half for the twentyfifth percentile, the mortality profile of the top half for the seventy-fifth percentile, and the average mortality profile for the fiftieth percentile.

Overall, women experience higher IRRs and NPVs compared to men because of their longer life expectancies. Men at all income levels have IRRs that are below the 2 percent level that would be obtained from a safe investment; correspondingly, their NPVs are always negative. In all cohorts, women at the median income and below obtain IRRs that are above 2 percent (and therefore have positive NPVs). In the 1915 and 1923 cohorts, women at the seventy-fifth percentile obtain IRRs that are below 2 percent (and negative NPVs); in later cohorts, these high-income women also obtain IRRs that are above 2 percent. In general, for both men and women, later cohorts experience higher IRRs and NPVs than earlier ones. This is attributable to increases in life expectancy for these later cohorts.

For the 1915 cohort, differential mortality makes virtually no difference to the IRRs earned by women, and a relatively small difference to the IRRs earned by men (it lowers the IRR by 0.21 percentage points for low-income men, and raises it by 0.24 percentage points for high-income men). The changes in the NPVs for women are in the $\$ 100$ to $\$ 200$ range (with the NPV of the twenty-fifth percentile falling, and the NPV of the seventyfifth percentile rising), while the changes in the NPVs for men are in the $\$ 1,000$ to $\$ 2,000$ range. For younger cohorts, however, differential mortality has a significantly larger effect, reflecting the fact that mortality inequality is much larger for the younger cohorts. For example, in the 1938 cohort, 
Results for stylized workers

\begin{tabular}{|c|c|c|c|c|c|c|}
\hline & \multicolumn{3}{|c|}{ Internal Rate of Return } & \multicolumn{3}{|c|}{$\begin{array}{l}\text { Net Present Value } \\
\text { (at age 20, } 2008 \text { dollars) }\end{array}$} \\
\hline & $\begin{array}{c}\text { Unadjusted } \\
(\%)\end{array}$ & $\begin{array}{l}\text { Adjusted } \\
(\%)\end{array}$ & $\begin{array}{l}\text { Difference } \\
(\%)\end{array}$ & Unadjusted & Adjusted & Difference \\
\hline \multicolumn{7}{|l|}{1915} \\
\hline Female 25th & 3.09 & 3.06 & -0.02 & $4,283.05$ & $4,179.22$ & -103.82 \\
\hline Female 50th & 2.09 & 2.09 & & 692.89 & 692.89 & \\
\hline Female 75 th & 1.24 & 1.26 & 0.02 & $-9,083.35$ & $-8,897.23$ & 186.12 \\
\hline Male 25th & 0.35 & 0.14 & -0.21 & $-17,602.32$ & $-18,967.45$ & $-1,365.13$ \\
\hline Male 50th & -0.53 & -0.53 & & $-39,099.20$ & $-39,099.20$ & \\
\hline Male 75th & -0.99 & -0.75 & 0.24 & $-56,917.35$ & $-54,783.07$ & $2,134.29$ \\
\hline \multicolumn{7}{|l|}{1923} \\
\hline Female 25th & 3.77 & 3.64 & -0.13 & $8,826.74$ & $7,936.54$ & -890.21 \\
\hline Female 50th & 2.64 & 2.64 & & $6,313.99$ & $6,313.99$ & \\
\hline Female 75 th & 1.86 & 2.00 & 0.13 & $-1,984.42$ & -63.21 & $1,921.21$ \\
\hline Male 25th & 1.03 & 0.71 & -0.33 & $-12,629.79$ & $-15,707.69$ & $-3,077.90$ \\
\hline Male 50th & 0.29 & 0.29 & & $-32,843.89$ & $-32,843.89$ & \\
\hline Male 75th & -0.05 & 0.33 & 0.38 & $-48,684.20$ & $-42,905.36$ & $5,778.84$ \\
\hline \multicolumn{7}{|l|}{1931} \\
\hline Female 25th & 4.01 & 3.79 & -0.22 & $11,287.51$ & $9,493.64$ & $-1,793.87$ \\
\hline Female 50th & 2.81 & 2.81 & & $8,773.85$ & $8,773.85$ & \\
\hline Female 75 th & 2.06 & 2.30 & 0.24 & 967.94 & $5,105.37$ & $4,137.43$ \\
\hline Male 25th & 1.19 & 0.78 & -0.42 & $-12,334.26$ & $-17,010.02$ & $-4,675.75$ \\
\hline Male 50th & 0.58 & 0.58 & & $-31,813.90$ & $-31,813.90$ & \\
\hline Male 75th & 0.33 & 0.81 & 0.49 & $-46,426.82$ & $-36,513.17$ & $9,913.65$ \\
\hline \multicolumn{7}{|l|}{1938} \\
\hline Female 25th & 4.41 & 4.14 & -0.27 & $15,994.82$ & $13,224.33$ & $-2,770.49$ \\
\hline Female 50th & 3.15 & 3.15 & & $14,632.08$ & $14,632.08$ & \\
\hline Female 75 th & 2.41 & 2.71 & 0.30 & $7,805.31$ & $14,528.04$ & $6,722.73$ \\
\hline Male 25th & 1.51 & 1.07 & -0.44 & $-9,156.76$ & $-15,636.60$ & $-6,479.83$ \\
\hline Male 50th & 1.00 & 1.00 & & $-27,309.54$ & $-27,309.54$ & \\
\hline Male 75th & 0.75 & 1.28 & 0.53 & $-41,733.36$ & $-27,131.87$ & $14,601.48$ \\
\hline
\end{tabular}

differential mortality reduces the IRR from 1.51 percent to 1.07 percent for low-income men, and raises it from 0.75 percent to 1.28 percent for highincome men. In fact, once differential mortality is taken into account, males in the seventy-fifth percentile in the two later cohorts receive higher rates of return than males in the twenty-fifth percentile. At least in terms of rates of return, an apparently progressive system becomes regressive. For men in earlier cohorts, and for women in all the cohorts, Social Security remains progressive, although the progressivity is reduced when differential mortality is taken into account.

Our results for stylized workers are comparable to those reported in Garrett (1995), who computes IRRs and NPVs for stylized men, women, and couples in the 1925 birth cohort at different income levels. There are a few significant differences between Garrett's computation and ours. As discussed in the literature review, Garrett uses mortality differentials based on current income that were estimated in the 1960s and 1970s in Kitagawa and Hauser 
(1973). Garrett also does not adjust for age in computing wage profilesfor example, in each year, a fiftieth percentile worker earns the income of the median family. (However, he reports in a footnote that adjusting for age does not change his results substantially.) Finally, Garrett allows mortality to vary according to whether a worker is in the bottom quintile or the top four quintiles. Thus, differential mortality lowers the IRRs for the twentieth percentile and below and raises the IRRs for all others. Moving from homogeneous to differential mortality reduces the IRR earned by twentieth percentile males from 1.62 percent to 0.47 percent, raises the IRR earned by the fiftieth percentile male from 0.85 percent to 1.06 percent, and raises the IRR earned by the seventy-fifth percentile male from 0.53 percent to 0.74 percent. Thus, differential mortality makes Social Security regressive. Our comparable results for the 1923 cohort are somewhat more modest. After adjusting for differential mortality, the twenty-fifth percentile male still earns the highest IRR. While the seventy-fifth percentile male earns a slightly higher return than the fiftieth percentile male, the difference is small. This is probably because the correlation between lifetime income and mortality is weaker than the correlation between current income and mortality (which is confounded by reverse causality).

Our next step is to compute IRRs and NPVs for the actual workers in our sample of Social Security beneficiaries. These results are summarized in figures 6.2 to 6.5. Figures 6.2 and 6.3 show the average IRRs for men and women, respectively, for different levels of AIME (where the AIME for each cohort is given in current dollars for the year that workers in that cohort turned sixty). Averages are calculated over $\$ 100$ intervals. The two series labeled "homogeneous" and "differential" show the average IRR earned by workers at each level of AIME under the assumptions of homogeneous and differential mortality, respectively. The two straight lines on the graphs represent linear approximations of these average IRR curves.

Under differential mortality, a worker's mortality profile depends only on whether he or she is in the top half or bottom half of the lifetime earnings distribution. As discussed before, we classify workers into the top half and bottom half of the earnings distribution based on their nonzero earnings between the ages of forty-five and fifty-five-this classification was chosen to be consistent with Waldron (2007). This measure of lifetime income appears to be highly correlated with AIME and therefore creates a break in the "differential" line at roughly the fiftieth percentile of AIME-workers below the fiftieth percentile see a decline in their IRR, while workers above the fiftieth percentile see an increase in their IRR. As a result, the average IRR initially falls with AIME, then rises briefly, and falls again. It is likely that, had differential mortality data been available for finer income groups, mortality inequality would affect the average IRR in a more continuous way.

These results are consistent with the results for the stylized workers. Across cohorts, all but the lowest income men earn IRRs that are below 2 percent. 

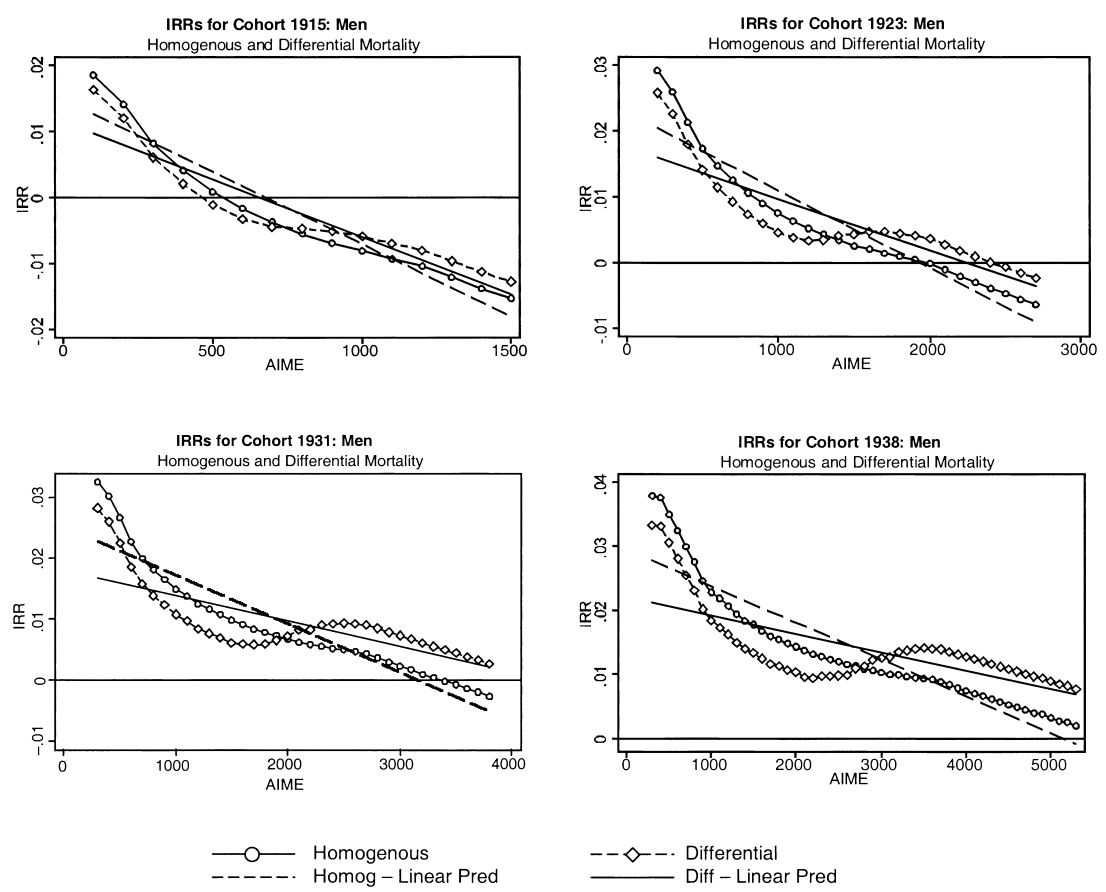

Fig. 6.2 Internal rates of return for men
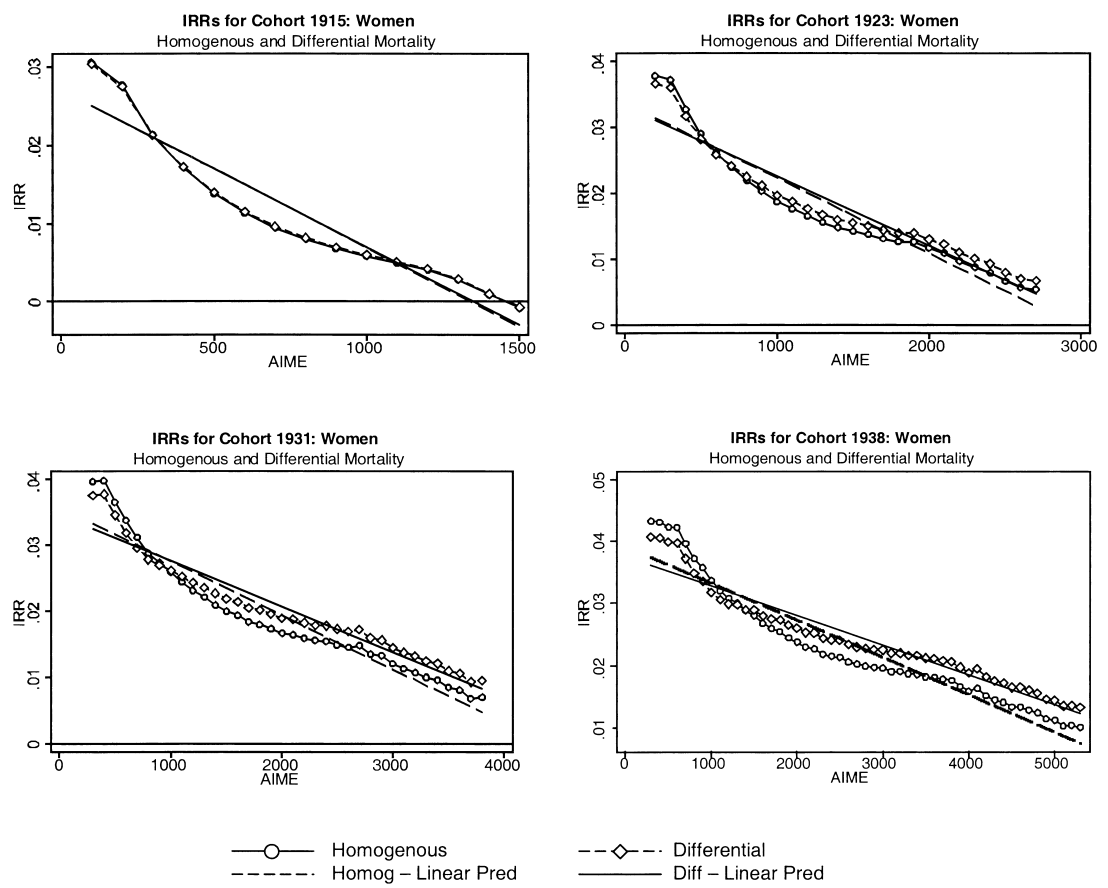

Fig. 6.3 Internal rates of return for women 
At each level of AIME, women earn higher IRRs than men, and more recent cohorts earn higher IRRs than earlier ones. Differential mortality makes virtually no difference for women in the earlier cohorts and only a small difference for men. For more recent cohorts, differential mortality makes a substantial difference for men and a modest difference for women.

Figures 6.4 and 6.5 show the NPVs for men and women, respectively, at different levels of AIME. Again, the "homogeneous" and "differential" series show the average NPVs for all workers at each level of AIME, while the other two lines are linear approximations. Men at most income levels receive negative NPVs, while lower-income women generally receive positive NPVs. The NPVs at all income levels are higher for later cohorts. Again, the impact of differential mortality is pronounced for men in later cohorts. For instance, note in the fourth panel of figure 6.4 that men born in 1938 with an AIME of $\$ 3,500$ have a higher (albeit negative) NPV from Social Security than do men in the same cohort with an AIME of $\$ 2,000$. Once again, at least in particular income ranges, the program has turned regressive. The impact on differential mortality on progressivity is more modest for women and for men in earlier cohorts.

\subsection{Conclusion}

Social Security is the largest program of the federal government and is thought to be progressive in that it offers workers with low lifetime earnings a better retirement deal than those with high lifetime earnings. The mechanism to achieve this progressivity is the highly nonlinear benefit (PIA) formula. In this chapter, we incorporate the latest evidence on mortality differences of those with above-median and below-median lifetime earnings. Since Social Security retirement benefits are paid out in the form of inflation-indexed life annuities, differential mortality, and therefore life expectancies, have the potential to reverse the progressive impact of the PIA formula.

The Waldron and Cristia studies published in 2007 indicate that there is more mortality inequality for men than for women and that the level of mortality inequality grew from birth cohort to birth cohort between those born between 1912 and 1915 and those born between 1936 and 1938. For example, the extra life expectancy at age sixty of men in the top half of the earnings distribution relative to those in the bottom half grew from 1.35 years for the 1915 birth cohort to 3.67 for the 1939 cohort. The extra lifetime for women in the top half of the earnings distribution relative to those in bottom half grew from nil in the 1915 birth cohort to 2.79 years in the 1939 cohort.

The growing mortality inequality has the straightforward effect of reducing the progressivity of Social Security. By the 1931 and 1939 birth cohorts, it is no longer true that the retirement portion of the Social Security system offers a better deal for those in the twenty-fifth percentile of the earnings distribution than those in the seventy-fifth percentile, at least in terms of 

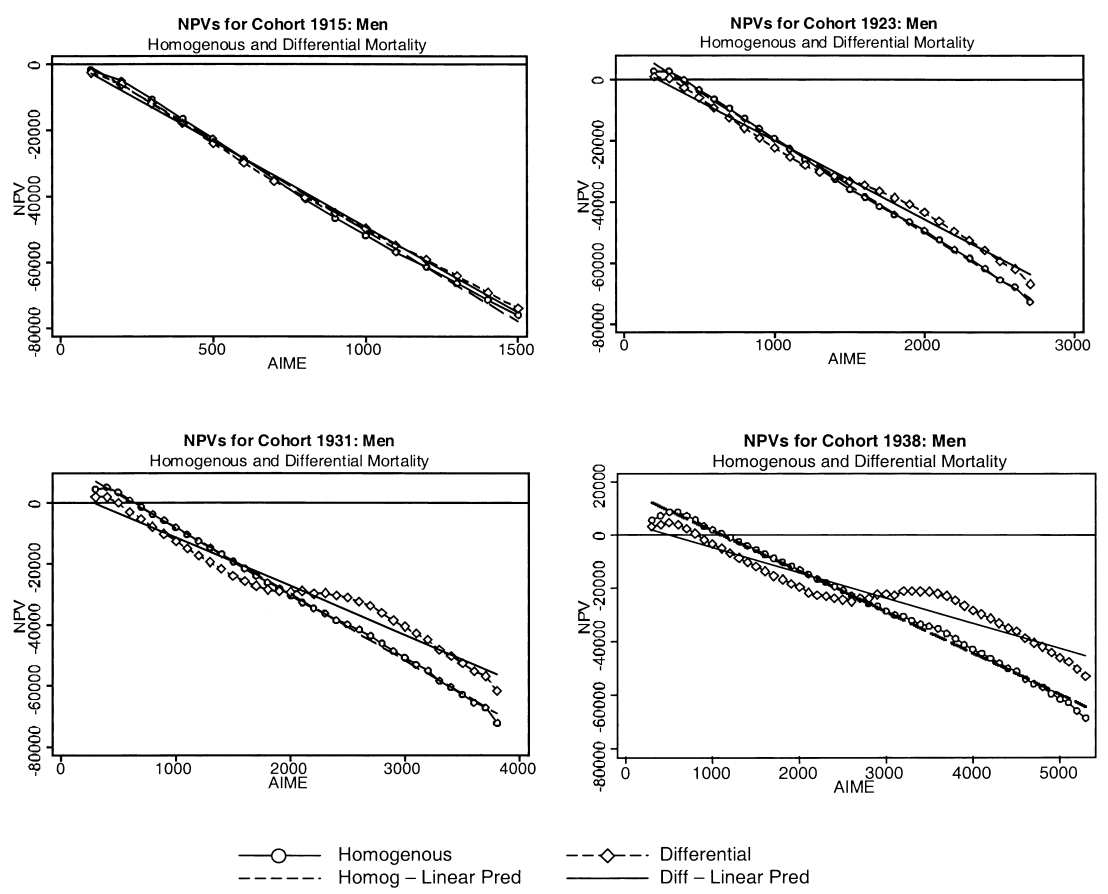

Fig. 6.4 Net present value for men
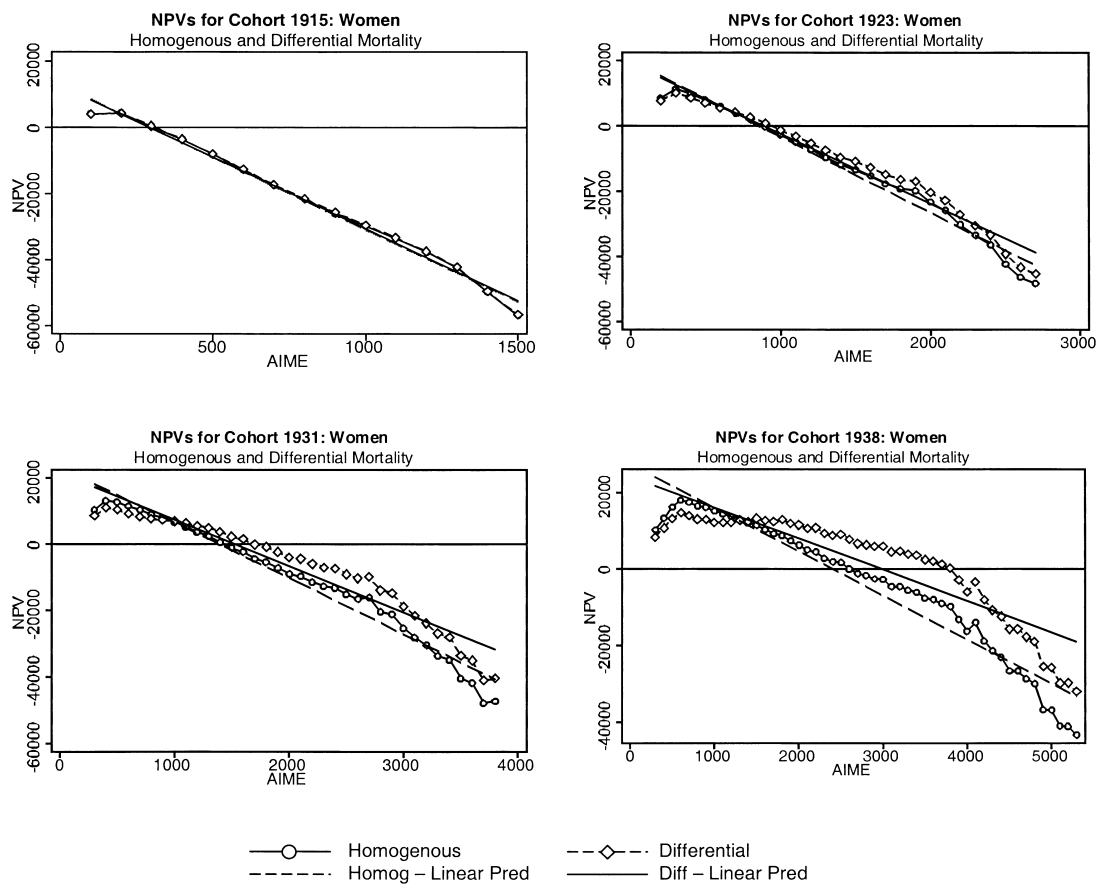

Fig. 6.5 Net present value for women 
rates of return. For women, the system has remained progressive, but much less so than if mortality inequality is ignored.

There is considerable room for further research on mortality inequality. For instance, it would have been useful to have a finer gradation of income categories and it would be interesting to know something about mortality inequality among younger cohorts such as the baby boomers. Social Security has the data for such studies, but it is not readily available in public use files. We think further work in this area is certainly warranted.

\section{References}

Aaron, H. 1977. Demographic effects on the equity of Social Security benefits. In The economics of public services, ed. M. Feldstein and R. Inman, 151-73. London: Macmillan Press.

Congressional Budget Office (CBO). 2006. Is Social Security progressive? Economic and Budget Issue Brief, December 15. Washington, DC: GPO.

. 2008. Growing disparities in life expectancies. Economic and Budget Issue Brief, July 16. Washington, DC: GPO.

Coronado, J., D. Fullerton, and T. Glass. 2000. The progressivity of Social Security. NBER Working Paper no. 7520. Cambridge, MA: National Bureau of Economic Research, February.

Cristia, J. 2007. The empirical relationship between lifetime earnings and mortality. Congressional Budget Office Working Paper 2007-11, August.

Duggan, J. E., R. Gillingham, and J. S. Greenlees. 2006. Mortality and lifetime income: Evidence from Social Security records. U.S. Treasury Office of Economic Policy Research Paper no. 2007-01.

Garrett, D. 1995. The effects of differential mortality rates on the progressivity of Social Security. Economic Inquiry 33 (3): 457-75.

Jemal, A., E. Ward, R. N. Anderson, T. Murray, and M. J. Thun. 2008. Widening of socioeconomic inequalities in U.S. death rates, 1993-2001. PLoS 3 (5): e2181.

Kitagawa, E. M., and P. M. Hauser. 1973. Differential mortality in the United States: A study in socioeconomic epidemiology. Cambridge, MA: Harvard University Press.

Liebman, J. 2001. Redistribution in the current U.S. Social Security system. NBER Working Paper no. 8625. Cambridge, MA: National Bureau of Economic Research, December.

Rogot, E., P. D. Sorlie, and N. J. Johnson. 1992. Life expectancy by employment status, income, and education in the National Longitudinal Mortality Study. Public Health Reports 107 (4): 457-61.

Singh, G. K., and M. Siahpush. 2006. Widening socioeconomic inequalities in U.S. life expectancy, 1980-2000. International Journal of Epidemiology 35 (4): 969-79.

Steuerle, C. E., and J. M. Bakija. 1994. Retooling Social Security for the 21 st century. Washington, DC: Urban Institute Press.

Waldron, H. 2007. Trends in mortality differentials and life expectancy for male Social Security-covered workers, by socioeconomic status. Social Security Bulletin 67 (3): 1-28. 